\title{
Contracultura y gráficas urbanas
}

\section{Counterculture and urban graphics}

TIPO DE TRABAJO: Comunación virtual.

\author{
PALABRAS CLAVE
}

Espacio público, contracultura, globalización, micropolítica, arte urbano, colectividad.

\section{KEY WORDS}

Public space, counterculture, globalization, micropolitics, urban art, community.

\section{RESUMEN}

El mundo actual se articula en torno a conceptos de globalización y universalización. El tema en sí mismo ya muestra la plasticidad de los falsos conceptos de mundo, que pueden corresponder tanto a la idea de totalidad acabada, como a la de pluralidad irreductible (el mundo que está hecho de mundos). Hoy en día, esta tensión entre lo unitario y lo plural es más evidente que nunca. No podemos explicar el comportamiento de las personas por referencia a los valores o normas establecidas en una cultura coherente, sino por el recurso de aquello desconocido, a la espontaneidad inventiva de la acción. Esto lo podríamos definir como ese infinito sin límites que caracteriza un comportamiento hacia ninguna definición conocida, en lo que consideraríamos una expresión contracultural. En un momento como este, aparecen prácticas subversivas en la manera que tenemos de experimentar nuestro entorno. Un nuevo dinamismo que inventa y compone integrando procesos de educación social colectiva. Analizaremos la capacidad de actuación de las artes (sin distinciones entre baja y alta cultura) en la proliferación de imágenes en la actualidad. Los conceptos de imagen y de visibilidad explorados a partir de la idea de que las estrategias de intervención en la ciudad pueden oscilar, desde los grandes gestos a los más pequeños, desde los más duraderos a los más efímeros. Grafías urbanas reflejadas en imágenes y textos ofrecidos por autores identificados o anónimos, a pie de calle, que transforman nuestro devenir diario. Estos gestos se tornan modelos de ocupación temporal del espacio público, desvelando la condición micropolítica de los otros modelos dominantes de producción de subjetividad, y se materializan en poetizaciones que continuamente se elaboran en el espacio urbano.

\section{ABSTRACT}

The current world is articulated around concepts of globalization and universalization. The subject itself already shows the plasticity of the false concepts of the world, which may correspond both to the idea of the finished totality, and to that of irreducible plurality (the world that is made of worlds). Nowadays, this tension between the unitary and the plural is more evident than ever. We cannot explain the behavior of people by reference to the values or norms established in a coherent culture, but by the resource of the unknown, to the inventive spontaneity of the action. This we could define as that infinite without limits that characterizes a behavior towards an unknown definition, in what we would consider a countercultural expression. At a time like this, subversive practices appear in the way we experience our environment. A new dynamism that invents and composes integrating collective social education processes. We will analyze the performance capacity of the arts (without distinctions between low and high culture) in the proliferation of images at present. The concepts of image and visibility explored from the idea that the strategies of intervention in the city can range from big gestures to the smallest, from the most durable to the most ephemeral. Urban graphics reflected in images and texts offered by identified or anonymous authors, at street level, that transform our daily becoming. These gestures become models of temporary occupation of the public space, revealing the micropolitical condition of the other dominant models of the production of subjectivity, and materialize in poetizations that are continually elaborated in the urban space. 


\section{INTRODUCCIÓN}

Cuando hablamos del espacio público y de su capacidad de promover la integración mediante procesos de educación social colectiva encontramos su coherencia en una mezcla y una convivencia social que es positiva. Estos planteamientos se exponen como una manera de experimentar la ciudad, entre muchos otros relatos subalternizados que pueden acompañar este paradigma. La ciudad es una figura espacial del tiempo donde se reúne el presente, el pasado y el futuro. Es decir, está dotada de capas superpuestas como a continuación veremos. La construcción por la que pasan las ciudades es paralela al nacimiento de una nación: es, por tanto, una ciudad política ${ }^{1}$. Desde este punto de vista, la ciudad es al mismo tiempo una ilusión i una alusión, de la misma forma que ocurre con la arquitectura que edifica los monumentos más representativos de una ciudad. Esto podría responder a lo que Augé denominó como movilidad sobremoderna, un nomadismo diferente del que metafóricamente es utilizado para denominar la movilidad actual. La comunicación general instantánea, los movimientos de población y la circulación de productos, imágenes o información. La ideología de la globalización nos muestra la apariencia o la evidencia y esta transformación responde a aspectos como las fronteras, la urbanización, la migración, el viaje o la utopía.

No podemos explicar el comportamiento de las personas en referencia a una visión universalista de la globalización, sino todo lo contrario. La espontaneidad, la inventiva de nuestras acciones cotidianas condicionan ese infinito sin límites que caracteriza un comportamiento que ninguna definición de los valores establecidos y estables puede acotar. Esto se ha producido en el curso de distintas redistribuciones de las oportunidades de la vida de las personas en relación con un proyecto común, unos cambios que se efectúan sucesivamente. Constatamos que ha habido una sucesión de sistemas y que esta sucesión ha ocasionado una crisis dolorosa, también trágica, producida por la destrucción de un tipo de momento en el que todavía no se ha definido el siguiente. Este espaciotiempo es inestable pero también se configura como una oportunidad única donde actuar. En un momento como este es donde aparecen las prácticas espontáneas en la manera que tenemos de experimentar nuestro entorno, de afrontar la realidad de una manera subversiva y de asumir la necesidad de que una sociedad de paso a otra. Podríamos acotarlo como que un nuevo dinamismo invente y componga una propuesta por ahora desconocida de los elementos de la vida en una configuración inédita. Las personas ignoramos por completo el mundo en el cual penetramos sino nos ligamos al mundo conocido, y precisamente podemos conocer el mundo cuando lo experimentamos, lo usamos y proponemos sobre él.

La característica básica de estas prácticas sería el uso de la ciudad con el concepto Do-lt-Yourself (hazlo tú misma), posteriormente de haber comprado un futuro que nunca llega. Podríamos considerar este concepto de la cultura punk del DIY como un posicionamiento que se puede enfocar desde diferentes posicionamientos culturales o disciplinas, como el urbanismo. Después de este primer empuje de empoderamiento por parte de la ciudadanía, surgieron lo que actualmente se denomina movimientos DIWO, Do-It-Yourself-WithOthers (hazlo tú misma con otras). Concepto que engloba una parte comunitaria que el anterior concepto no abarcaba. Al mismo tiempo se trata de otro fenómeno contracultural trasladable a cualquier otro ámbito de la vida cotidiana. Esta ética está asociada a movimientos anticapitalistas, ya que rechaza la idea de tener que comprar siempre a las otras personas las cosas puede o no necesitar. El movimiento punk se caracterizó por hacer esta filosofía para de él en la confección de su propia estética o en la forma de organización de sus sistemas de trabajo, comunicación, edición y distribución. Esta herencia fue heredada por otros movimientos contraculturales como el hardcore punk, el indie o las contraculturas denominadas alternativas.

En Valencia, es curioso pasear o hacer deporte por el antiguo cauce del río Túria y observar como tangencialmente al camino principal (donde diariamente circulan multitud de personas en bicicleta, corriendo o a pie), hay diferentes caminitos o sendas que se han ido construyendo con el paso incansable de inumerables pies que lo han transformado en un recorrido fijo, más cómodo para los runners porque por el césped y la tierra las rodillas no padecen tanto. También más tranquilo, para quien decide aventurarse por estos caminos paralelos y salir del tradicional, que normalmente se encuentra fuertemente masificado.

Estas líneas, en un primer momento imaginarias y dibujadas simbólicamente en nuestras cabezas. Se convierten en un trazo legible en nuestros entornos gracias a la experimentación. Algunas personas definen esto como desire lines o líneas de deseo, un término utilizado por el filósofo francés Gaston Bachelard en los años cincuenta. En contraposición a los movimientos políticos organizados, este diseño urbano espontáneo representa el simple deseo de transformar eso que tenemos construido a partir de nuestros propios criterios. Y por esto, a parte de ganas, tenemos el derecho percibido de cumplirlo para humanizar el diseño de nuestros espacios.

\footnotetext{
1 Augé, Marc. Por una antropología de la movilidad. Editorial Gedisa, Barcelona, 2007. Págs. 73 a 79.
} 


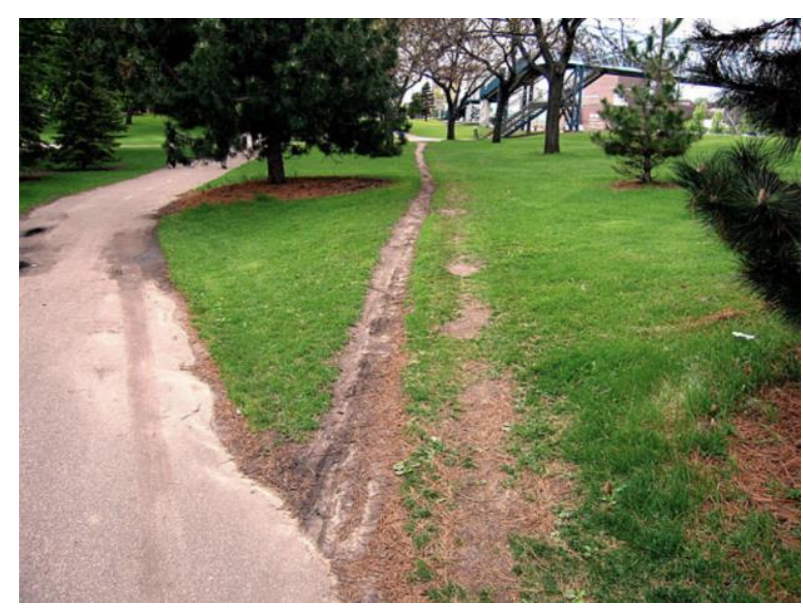

Figura 1. Desire lines.

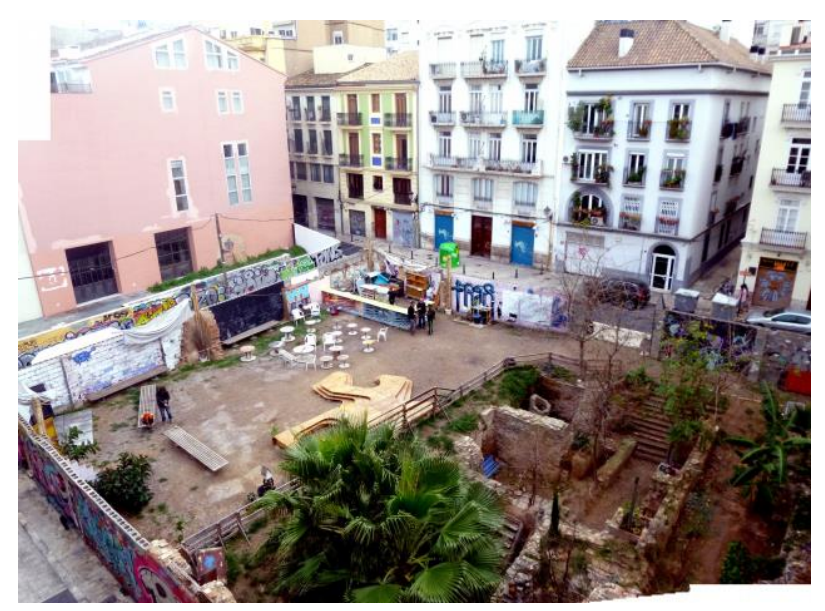

Figura 2. Solar Corona. Foto de Héctor Hernández, 2013.

Todo y que la tendencia de los últimos años ha abierto una mayor sensibilidad por parte de las instituciones a los usos de los espacios por parte de la ciudadanía, normalmente los especialistas o gestores públicos no actúan frente a esta posible situación. Pueden ignorarlo o pueden penalizar tal comportamiento. Y la cuestión que más interesante nos podría resultar es que tales comportamientos, pueden ser observados y así utilizarlos como pretexto para adaptar el diseño de nuestros espacios de convivencia. ${ }^{2}$

\section{METODOLOGÍA}

Estamos describiendo una fórmula de hacer que parte del aprendizaje experiencial. Es decir, con los usos construimos el significado. Esto nos proporciona una oportunidad extraordinaria de crear espacios para construir aprendizajes significativos desde la autoexploración y la experimentación. Esta metodología experiencial está muy relacionada con el aprendizaje, la manera en que tenemos de asimilar conceptos, relacionarnos con ellos y aplicarlos en el contexto socio-cultural que nos rodea. Teorías como el learning by doing, learning by experiencie o hands-on learning están desarrollando estas ideas con autores como John Dewey o David Kolb. Mediante este proceso de aprendizaje adquirimos habilidades, conocimientos y conductas como resultado del análisis de la observación y de la experiencia. Estos cambios como hemos podido comprobar anteriormente pueden alcanzar diversos grados de estabilidad, y se producen como resultado de estímulos y respuestas.

Estos aprendizajes desde un punto de vista individual, pueden convertirse en aprendizajes colectivos a medida que se van socializando, compartiéndolos en grupo desde la flexibilidad cognitiva. Esto hace que sean integrados por la comunidad, y es aquí donde adquiere sentido estas experiencias de ocupación y transformación del espacio público por parte de un colectivo, que ha asimilado estas conductas (relacionadas con el andar, con el juego, con la comida, con la actividad física, etc.) convirtiéndose en agentes activos y propositivos del espacio social que habitamos.

El aprendizaje es un proceso mediante el cual, el conocimiento se crea en base a la transformación de una experiencia. Es permanente y activo, respondiendo a un desarrollo en el cual los procesamientos de la información implican que los aprendices deben construir y reorganizar esos conocimientos que están adquiriendo en su estructura cognitiva por medio de sus propios niveles de representación. Construimos estos espacios, estas acciones, obras artísticas, etc. en base al conocimiento que tenemos adquirido a partir de nuestras propias realidades, experiencias previas, valores instaladas o normas aceptadas. Todo esto es lo que reflejamos en una representación social. Construir significado es una acción colectiva (por ello no todas las personas recibimos el mismo mensaje de una representación social), y esta acción colectiva es la que construye o desconstruye aprendizajes.

La teoría APRENEX / Aprendizaje Experiencia, es holística y combina la experiencia, la percepción, la cognición y el comportamiento. Basada también en el constructivismo, es utilizada de manera consciente, planificada y dirigida para poder ser adaptada como sistema formativo. Lo curioso que debemos plantearnos, es que describiendo estas acciones espontáneas y estas metodologías de aprendizaje, estamos hablando de la transformación de las personas como individuos en relación con sus competencias, su liderazgo, su capacidad de tomar decisiones. Pero también de la inter-relación con el resto de personas, la comunicación efectiva, la conformación de equipos de trabajo, la concienciación de la seguridad y la salud, el fortalecimiento de los valores y la cultura. Esta fórmula de situarse en el mundo, puede ser una filosofía de vida que reflexiona sobre los hechos para provocar los aprendizajes y luego, tomar las acciones pertinentes ofreciendo la posibilidad de una evolución social colectiva basada en el conocimiento de nuestros errores y aciertos.

\footnotetext{
${ }^{2}$ Hurst, Marcus. Las líneas del deseo nos ayudan a diseñar ciudades más humanas. Consultado En: http://yorokobu.es/las-lineas-del-deseo/ $(04 / 02 / 2019$ a las $10.02 \mathrm{~h})$.
} 


\author{
Tomás Marquina, Daniel. \\ Contracultura y gráficas urbanas \\ IV Congreso INTERNACIONAL DE INVESTIGACIÓN EN ARTES VISUALES ANIAV 2019 \\ IMAGEN [N] VISIBLE] \\ http://dx.doi.org/10.4995/ANIAV.2019.9370
}

\title{
DESARROLLO
}

Anteriormente describíamos esas maneras de "hacer visible lo invisible" mediante las líneas de deseo o las acciones colectivas. En esa misma línea, el fotógrafo holandés Jan Dirk Van der Burg ha publicado un libro sobre las desire lines. ${ }^{3}$ Los holandeses tienen su propio nombre para describir este fenómeno antropológico, nombre muy poético como es Olifantenpaadjes o camino de elefantes.

A partir de aquí podríamos citar el proyecto de Ciudades Ocasionales que parte del concepto de post-it City acuñado por Giovanni La Varra 4 para designar un dispositivo de ciudad contemporánea que es inherente a las dinámicas de la vida colectiva dentro de los canales convencionales. Los fenómenos que podrían poner en esta categoría son los que estamos comentando, y que apuntan a modelos de ocupación temporal del espacio público para diferentes actividades y desvelan la condición micropolítica de los modelos dominantes de producción de la subjetividad, de lo que hemos denominado con anterioridad como las poetizaciones elaboradas en el espacio urbano. Esto, también se podría denominar como gestos Post-it de expresión de noticias explícitas de una subjetividad presente en todas nuestras ciudades. Las ocupaciones temporales del espacio público ideadas ya sea desde el ingenio, desde la espontaneidad, el reciclaje o la acción denotan una subjetividad singularizada dispuesta a instituir de forma autónoma un imaginario social diferente al hegemónico. Esto convierte estas prácticas, casi de manera ineludible, en actos de sabotaje. Pero esta es precisamente su discreta semilla revolucionaria según la cual, gracias a este retorno de la subjetividad se podrán fundar y articular nuevos mecanismos de subjetividad. ${ }^{5}$

A parte de estas creaciones esporádicas en lugares específicos, hay otros proyectos que son parte de iniciativas más amplias, donde podemos encontrar series de las mismas intervenciones en diferentes lugares, incluso en diferentes ciudades. En algunas ocasiones podríamos conectar estas acciones con posicionamientos ideológicos como el ecologismo, pero muchas otras veces hay que resaltar que no hay una consciencia real del impacto político de estas acciones y de la propuesta de mejora física que se está proporcionando de nuestro entorno. Esto va desde las instalaciones de bibliotecas temporales en cabinas telefónicas, instalaciones artísticas, tiendas ilegales, pintadas en vías ciclistas o en las calles, etc. Estas manifestaciones espontáneas (nos las podemos encontrar en mayor o menor medida, con mayor o menor visibilidad o repercusión en todas nuestras ciudades) también suponen en muchos casos otra vocación de pervivencia e introducen mecanismos de gestión urbana colectiva paralela al sector público institucionalizado. Esta espontaneidad también se combina con otro tipo de alianzas entre movimientos y asociaciones vecinales, empresariales o de la ciudadanía, que más o menos organizadas trabajan para mejorar y gestionar sus barrios y sus inquietudes políticas.

Un movimiento contracultural podría definirse como un conjunto de valores, tendencias y formas sociales que chocan con aquello que está establecido dentro de una sociedad. Teniendo en cuenta esta idea podríamos considerar como planteamientos contraculturales las expresiones sociales descritas en este artículo, ya que está expresión contracultural se encuentra implícita en estas fórmulas subversivas de la espontaneidad social. Podríamos definirla de igual modo como la realización, más o menos plena, de las aspiraciones e ideales de un grupo social minoritario. Las últimas décadas nos han mostrado como los diferentes movimientos contraculturales evolucionan hasta diferentes puntos: 1.Pueden caer en el olvido. 2.Permanecer en lo que conocemos como underground. 3.Desaparecer siendo engullidos por el sistema. 4.Afectar a la cultura hegemónica desde dentro, es decir, jugando a las reglas del juego.

\section{Acciones gráficas concretas en la esfera pública de nuestras ciudades}

El arte no es público porque esté al aire libre. Es [arte] público porque es una manifestación de actividades artísticas y estrategias que utilizan lo público como origen y tema de análisis. Es [arte] público a causa del género de preguntas que genera, y no por su accesibilidad o el número de espectadores. ${ }^{6}$

Este comentario, hecho por la crítica de arte Patricia Phillips, pone de relevancia por un lado como el arte público o las estrategias de intervención en la ciudad pueden oscilar desde los grandes gestos hasta los más pequeños, del tamaño de un autohadesivo. Por otra, como esto gestos se pueden situar como visibles para un mayor o menor número de público y en un grado más duradero o efímero. Estas prácticas, más englobadas dentro de la tendencia del street art o funcionando de una manera más autónoma o espontánea tienen una necesidad de comunicar de manera crítica las características de la ciudad que los envuelve. 0 bien mediante el dibujo o bien mediante las grafías. Aquí existe de nuevo una inconformidad, pero no tan sólo como práctica clandestina, sino también a una estética subversiva y a la corrupción del poder establecido. Estas prácticas se han institucionalizado por los movimientos sociales con una vocación contracultural.

\footnotetext{
${ }^{3}$ Se puede consultar todo el proyecto en el siguiente video resumen del propio artista. Consultado En: https://vimeo.com/24915224 (Consultado el 05/02/2019 a las $13.06 \mathrm{~h})$.

${ }^{4}$ La Varra, Giovanni. Post-it City: Los otros espacios públicos de la ciudad europea. D.A. Mutaciones, Barcelona, 2001. Págs. de 426 a 431.

${ }^{5}$ Se puede consultar más información sobre este proyecto en su página web En: http://www.ciutatsocasionals.net (05/02/2019 a las 13.23 h).

${ }^{6}$ Simoes, Daniela. De la defensa del Street Art y el Grafiti como vanguardias del arte público. Consultado En: http://www.emergenciaemergenciaemergencia.com/revista/index.php/issues/05/simoes/ (13/02/2019 a las 12.18 h).
} 
Sea cual sea el modo, siempre que se encuentre esta vinculación contextual, se presenta de manera potencial la posibilidad de cuestionar el orden social establecido y de este modo se puede ofrecer una visión crítica que despierte consciencias y sea coherente con las bases sobre las que ha nacido. Es decir, propiciar actitudes que estén en continuo cuestionamiento de las formas que nuestras representaciones culturales van adoptando, para que podamos identificar nuestras acciones dentro de un movimiento contracultural. Que cualquier expresión suceda de forma espontánea, ilegal o ajena a las instituciones no asegura su capacidad subversiva. Que una expresión se materialice dentro de un espacio considerado como regulado y por tanto institucionalizado no vacía de contenido o fuerza su propuesta.

Dentro de este ámbito podemos encontrar artistas vinculados al graffiti como Escif, que retrata temas de actualidad. Tanto de su ciudad natal, Valencia, como de los lugares que visita. Estos trabajos como se describe, tienen una fuerte vinculación con su ámbito contextual y componente común, se encuentran en la calle. Este elemento, la calle, es el que toma como espacio de investigación y es lugar donde plasma sus obras. A estas, les llama intervenciones. Aprovechando las paredes antiguas, descorchadas o tapiadas establece un diálogo con la pared. Sus intervenciones son críticas economicopolíticas y se encuentran situadas en el caso de Valencia en el distrito de Ciutat Vella. Así que, podemos ver alusiones al caso Gürtel, a la Primavera Valenciana, a los recortes económicos o incluso a la caída del ex rey Juan Carlos I durante la visita al Estado Mayor de la Defensa.

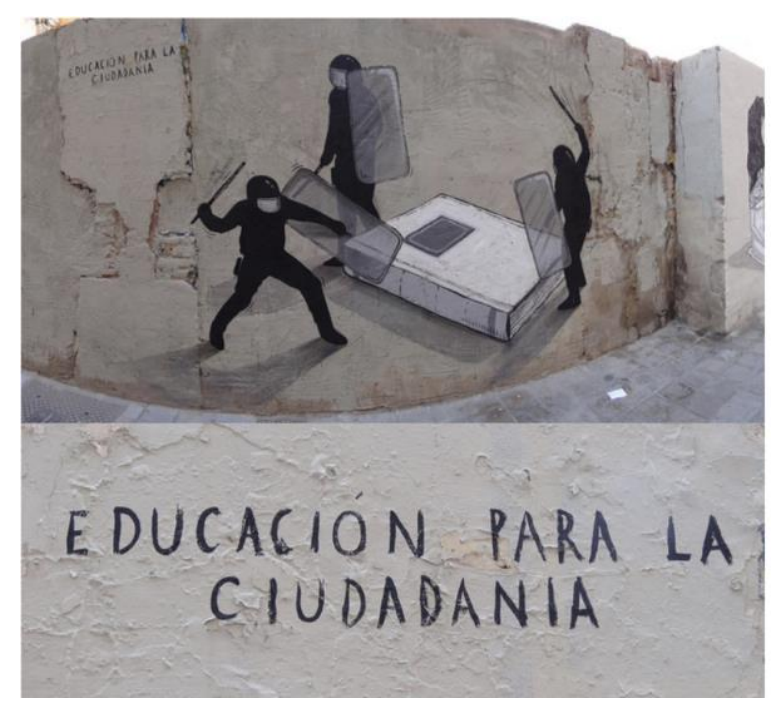

Figura 3. Escif en las calles de Ciutat Vella (València).

En el texto que introduce, muestra de igual modo el carácter reivindicativo que tienen sus trabajos:

Lo más interesante de las pinturas no es lo que pinta, sino lo que no se pinta. Una intervención en una pared marca un punto de atención en un espacio que tiene una historia concreta y un contexto determinado que condiciona profundamente su carácter. La pintura consigue invertir la soberbia con la que el hormigón se impone frente a las masas. Una pared pintada debe ser un límite para convertirse en una canal de comunicación abierto, con el cual se puede llegar a muchísima gente. ${ }^{7}$

De nuevo la calle se muestra en un marco entre la intervención y el espectador. Sin galería o museo. En este sentido que nos muestra este artista, toma del graffiti aquello que le interesa dejando de lado el Street art como una expresión que ya se ha visto fuertemente mercantilizada. Defiende estas intervenciones desde el prisma del arte de acción, no desde la pintura y se mantiene en el anonimato reivindicando el espacio público. Un espacio que se sostiene, según sus palabras "dentro de los parámetros del caos". Definiendo el caos como una "creación continua".

Esta primera aproximación hecha a través de personas que son conscientes de la potencialidad y dimensionalidad que su propuesta puede alcanzar. Lo hacen insertado dentro de una línea de trabajo que engloba muchas otras acciones que podrían ser analizadas. En este caso, podríamos decir que de alguna manera son acciones profesionalizadas que nos ofrecen una visión nueva de nuestras ciudades.

Dentro de estas ideas también debemos resaltar la práctica popular. Esas expresiones que visibilizan los latidos de una ciudad realizadas por personas anónimas desde otro prisma diferente a las intervenciones que hemos visto anteriormente.

${ }^{7}$ Andrés Durà, Raquel. Escif, el Banksy valenciano. Consultado En: http://www.lavanguardia.com/local/valencia/20141026/54418129758/grafiteroescif-banksy- valenciano.html (05/02/2019 a las $12.46 \mathrm{~h})$. 


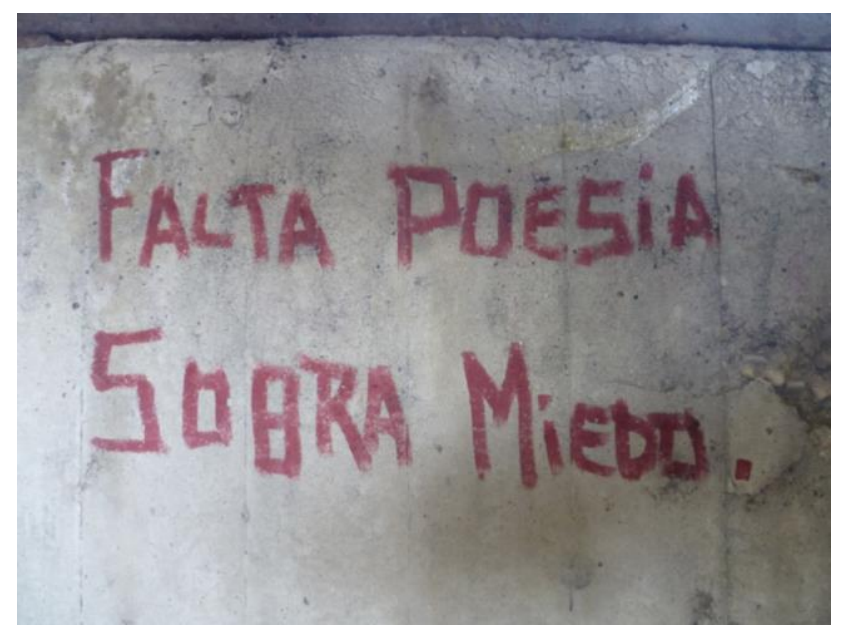

Figura 4. Pintada callejera.

De la expresión "Las paredes hablan" cultivada en la revuelta estudiantil de Mayo del 68 en París, se comprobó como este procedimiento era una medio eficaz para la difusión de las ideas. En las inscripciones de este momento se mezclaron indicaciones prácticas para los compañeros y compañeras, normas de conducta, citas de pensadores y poetas relevantes, el valor potencial insurrecto que en este aspecto aporta la auténtica poesía. Entre los nombres que se encontraban en aquel momento figuran en primer término los poetas surrealistas Bretón, Artaud, Peret o Tzara. Junto a pensadores como Marx o Bakunin. Del conjunto de normas, reflexiones y citas surge el principio de la importancia fundamental de la acción que en todo momento desborda las premisas teóricas. Este rechazo a los esquemas ideológicos previos justifica el acento que en este texto queremos situar sobre la espontaneidad del movimiento como única actitud eficaz para generar un cambio de paradigma real en la organización social.

Podríamos considerarlo casi, a modo de "justicia poética" que aparecen en nuestras calles día a día frases que nos pueden generan indiferencia o rechazo, ahora bien, si tenemos suerte también pueden enseñarnos a ver el mundo desde otra perspectiva. Falta sinceridad en nuestras calles y sobra hipocresía. Falta valor y sobran palabras. Falta amor y sobran convencionalismos. Faltan voces y sobran susurros. Falta horizonte y sobran lupas. Falta verdad y sobra mentira.

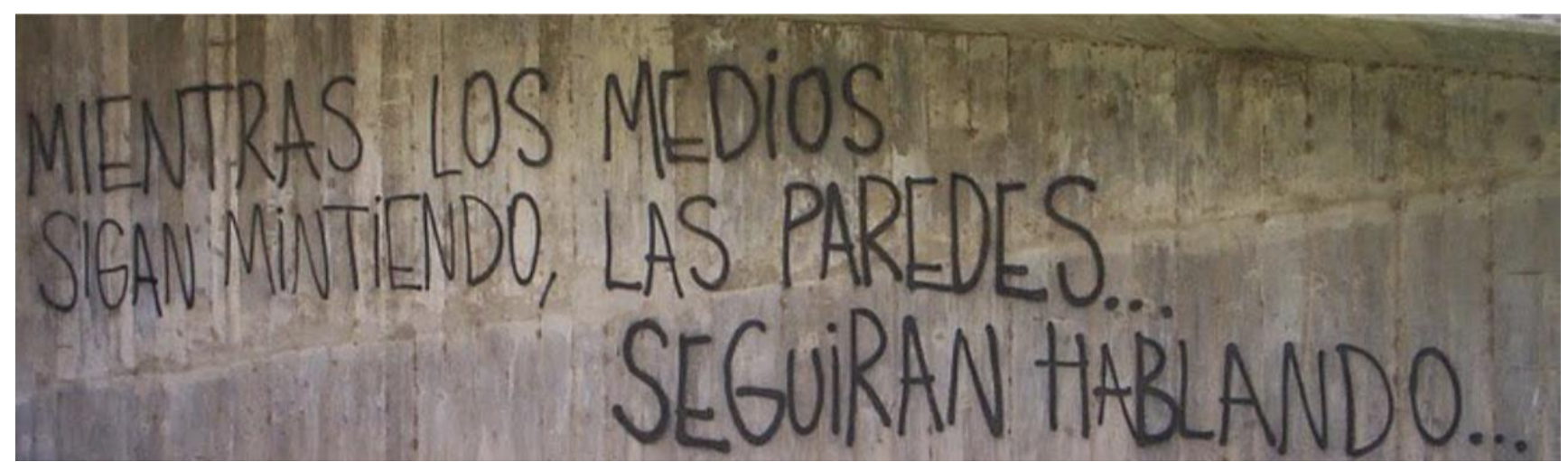

Figura 5. Pintada callejera.

\section{CONCLUSIONES}

Todo ello son ejemplos para señalar como todas las historias están en cualquier esquina, en cualquier espacio que transitamos día a día. Experimentar la ciudad de esta manera supone entrenar la mirada para entenderla desde otra perspectiva. El mismo ritmo diario que aplicamos a nuestras vidas nos marca la forma en que nos relacionamos. Por tanto, para seguir entendiendo nuevas fórmulas de relación con nuestros espacios, debemos hablar de igual modo de la velocidad en la cual lo estamos vivenciando. El ritmo de nuestros pasos nos puede marcar un camino nuevo a la hora de transitar por nuestras ciudades.

En este devenir existe a veces, alguien, que con mayor o menor intención señala sucesos, sentimientos, ideas, etc. o cualquier expresión que puede producir un quiasmo en nuestro transitar cotidiano por los espacios que vemos diariamente. Nuestra respuesta a 
estos estímulos puede ir de la indiferencia, al asombro. Del rechazo a la emoción. Encontramos algunas efímeras, otras más duraderas. Algunas de las que existe un registro, y otras de las que puede que nadie se haya preocupado ni de mirar (excepto el propio autor o autora). Pero todas estas grafías e imágenes subversivas se sitúan a nuestro alrededor para contarnos que nuestra realidad está construida a partir de capas. Y son estas expresiones contraculturales las que configuran esta manera de entender el mundo contado en primera persona y en un espacio de libertad por sus propios habitantes.

Libertad, porque en muchas de estas representaciones no existe la intención, no existe el peso de un discurso de poder cultural dominante, no existe la idea del "agrado" o la "utilidad social". Nos movemos en un terreno donde la expresión espontánea cuenta historias que configuran nuestro imaginario colectivo desde un lugar que nos es común a todas las personas, la calle. Son procedimientos que se insertan como cualidad micropolítica en la esfera pública de nuestras ciudades, dotando de cualidades plásticas y poéticas desde las paredes a los suelos. Estar atentas a estos pequeños acontecimientos es tarea ardua, puesto que diariamente las personas nos vemos sometidas a una infinidad de imágenes que en muchas ocasiones somos incapaces de abarcar. El tema de la visibilidad de estas historias cotidianas es una cuestión que en ocasiones puede escapar a nuestros intereses más inmediatos. Pero con certeza, las personas estaremos más conectadas con el mundo que nos rodea en la medida que sensibilicemos nuestros sentidos a las expresiones e ideas que surgen del otro. Una conexión mayor con nuestro entorno basada en el respeto y la idea de comunidad que deje translucir en ocasiones esa delgada membrana entre lo que es visible y lo invisible.

\section{FUENTES REFERENCIALES}

Alexander, J. (2000). Sociología cultural. Formas de clasificación en las sociedades complejas. Barcelona: Anthropos.

Appadurai, A. (2001). La modernidad desbordada. Dimensiones culturales de la globalización. México: Ed. F.C.E.

Ardenne, P. (2006). Un arte contextual. Creación artística en medio urbano, en situación, de intervención, de participación. Murcia, CENDEAC.

Brea, J. L. (2005). La epistemología de la visualidad en la era de la globalización. Madrid: Ed. Akal.

Castells, M. (2008). La era de la Información. Economía, sociedad y cultura, Volumen I. Madrid: Ed. Alianza.

D.A. (2001). Modos de hacer. Arte crítico, esfera pública y acción directa. Salamanca: Ediciones Universidad de Salamanca.

De Certeau, M. (1996). La invención de lo cotidiano. México: Ed. Universidad Iberoamericana.

Delgado, M. (1999). El animal público. Barcelona: Ed. Anagrama.

Garcia Canclini, N. (2012). Cultura y desarrollo. Barcelona: Ed. Paidós.

Jenkins, H. (2010). La cultura de la convergencia. Barcelona: Ed. Paidos.

Lefebvre, H. (1972). La vida cotidiana en el mundo moderno. Madrid: Alianza Editorial.

Mulhern, F. (2001). Culture/Metaculture. Londres: Routledge.

Ranciere, J. (2005). Sobre políticas estéticas. Barcelona: Ed. Museo de arte contemporáneo de Barcelona.

Rowan, J. (2016). Cultura libre de Estado. Madrid: Ed. Traficantes de sueños.

Sennet, R. (2012). Juntos. Barcelona: Ed Anagrama.

Zunzunegui, S. (2007). Pensar la imagen. País Vasco: Ed. Cátedra, Anaya. 